\title{
Structural performance of textile reinforced concrete sandwich panels under axial and transverse load
}

https://doi.org/10.1515/rams-2021-0015

Received Dec 17, 2020; accepted Dec 26, 2020

Abstract: The performance of textile reinforced concrete composite panels (TRCCPs) under the action of pseudostatic load up to collapse was evaluated. The test of TRCCPs under axial and transverse loading was conducted, and the results were compared with those for steel wire mesh reinforced-concrete composite panels (SMRCCPs). Ceramsite concrete was utilized as the panel matrix owing to its lightweight and insulation characteristics. The ultimate load bearing capacity, load-deformation and load-strain relationships, and failure modes were discussed and investigated in comparison with the findings of non-linear finiteelement-model (FEM) analysis and the analytic method on the basis of the reinforced concrete (RC) theory. The analysis results indicate that TRCCP is suitable for use as a potential structural member for a wall or slab system of buildings, and the typical RC theory can be applied to predict the ultimate load bearing capacity if modified suitably.

Keywords: Textile reinforced concrete; Composite panel; Sandwich panel; Reinforced concrete; Analytic method

\section{List of Nomenclature}

RC reinforced concrete

\footnotetext{
${ }^{\star}$ Corresponding Author: Junqing Hong: School of transport and
civil engineering, Nantong University, Nantong 226019, China;

*Corresponding Author: Junqing Hong: School of transport and
civil engineering, Nantong University, Nantong 226019, China; Email: hongjq@ntu.edu.cn; Tel.: +8651385012653

*Corresponding Author: Hai Fang: College of Civil Engineering, Nanjing Tech University, Nanjing 211816, China;

Email: fanghainjut@njtech.edu.cn; Tel.: +86 2558139869

Shaofeng Zhang: School of transport and civil engineering, Nantong University, Nantong 226019, China

Xunqian Xu: National and Local Joint Engineering Research Center of Technical Fiber Composites for Safety and Protection, Nantong University, Nantong 226019, China

Honglei Xie, Yuntian Wang: College of Civil Engineering, Nanjing Tech University, Nanjing 211816, China
}

ð Open Access. (C) 2021 J. Hong et al., published by De Gruyter. (cc) BY License

\section{Introduction}

Various types of reinforced concrete (RC) members have been widely used in civil engineering for several decades. However, deterioration of the concrete structure leads to corrosion of the rebar and of the structural durability and safety. The use of fiber reinforced concrete (FRC), which has short and discrete fibers distributed uniformly and oriented randomly, can considerably enhance the performance of concrete in multiple aspects, such as in terms of the tensile strength, crack resistance, ductility and toughness. However, FRC cannot completely replace the traditional RC due to its insufficient bearing capacity and economic factors. Textile reinforced concrete (TRC), which was developed in the late 20th century and is based on the fiber reinforced plastic (FRP) textile technique, can solve the abovementioned problems partly because of its excellent corrosion resistance and high strength performance. TRC can be divided into three categories depending on the components and applications: (a) the existing element reinforcement 
with the thin textile concrete panel (TCP) or textile reinforced mortar (TRM) as a permanent formwork [1-8]; (b) pure textile-reinforcement concrete component focusing on the thin shell and slab [9-12]; and (c) sandwich textilecomposite concrete component [13-17].

The TRC sandwich component, which is composed of FRP textile, concrete and light thermal insulation material, has attracted attention in recent years. In Europe and North America, the pre-cast RC cladding sandwich panel developed and popularized largely in building-industry area, because the structural, thermal, and architectural properties could be integrated into a single unit advantageously [13] Compared to traditional ordinary RC or FRC wythes, TRC thin wythes significantly improve the comprehensive performances of sandwich panels. Hegger and Horstmann [7] proposed wall and floor sandwich panels developed using a lightweight TRC precast product. Colombo et al. [15] and Babaie et al. [16] used analytical and numerical approaches to predict the behavior of a multi-layer precast panel $(1.5 \mathrm{~m}$ $\times 3.3 \mathrm{~m}$ ) fastened to a façade in the context of energy retrofit of existing buildings; the panel was composed of an inner insulation layer in polystyrene foam (EPS, thickness: 100 $\mathrm{mm}$ ) and two TRC outer faces (thickness: $10 \mathrm{~mm}$ ) through the shear connectors. Portal et al. [17], using four-point bending tests and three-dimensional nonlinear finite element analysis, focused on understanding of the flexural capacity of the developed textile reinforced-foamed-concrete composite elements.

To ensure the working performance of sandwich panels, several types of shear connectors have been introduced to provide structural continuity and integrity between the exterior plates [18]. The amount of longitudinal shear force transferred between wythes determines the degree of composite action of the panels: fully composite panels (FCPs), noncomposite panels (NCPs), and partially composite panels (PCPs). FCPs can transfer the shear force completely between two wythes and act as one unit, while NCPs act independently and PCPs can only transfer partial shear between the two aforementioned cases. Methods to predict the PCP behavior, specifically, approaches to consider the interlayer and the connectors accurately and conveniently, still represent a relatively complicated aspect [19]. In particular, compared to NCPs and PCPs, FCPs are superior as they bear more load with less material [20]. Moreover, the vested $\mathrm{RC}$ theory can be transformed easily to predict the behaviors of FCPs.

Experimental and theoretical studies have examined the structural performance influenced by shear connectors in sandwich panels [21]. The connectors, usually made of metallic and non-metallic materials, can be classified according to their shapes into two groups: non-continuous and continuous. Noncontinuous connectors include C-ties, M-ties, and Z-ties; and continuous connectors include bent wire, truss-shaped, and grid-type connectors [22]. Among these, solid concrete ribs can provide satisfactory composite effects and full composite action between wythes [23,24]. Bar-type glass-fiber-reinforced plastic (GFRP) shear connectors and truss-shape steel shear connectors were found to considerably improve the composite action [25-28]. In addition, experimental and theoretical studies indicated that carbon-fiber-reinforced-plastic (CFRP) grid connectors demonstrated excellent structural performance [29-32]. Naito et al. [33] compared 14 types of shear ties, including both non-continuous and continuous types of shear connectors (carbon steel, CFRP, and GFRP). Kang et al. [21] developed the design models to predict the design resistance of sandwich wall panels under bending in terms of their semi-composite action based on reliability analysis. Several types of continuous and non-continuous connectors have presented acceptable connecting capability even in nearly fully composite states; however, some concerns still remain, such as gradual transition into partial compositeness due to serviceability failures pertaining to early cracking, complicated forms of shear connectors, high costs, and complex analysis methods [31].

TRCCP (textile reinforced concrete composite panels), a type of TRC composite panel with TRC face plates and webs surrounding the insulated material, has the potential to be developed into a type of multi-functional integrated panel, combining structural and functional capacities, as shown in Figure 1. This panel adopts ceramsite concrete as the matrix and glass-fiber textile grid (GFTG) as the reinforcement. The textile grid, which is considerably more cost-effective against steel bar, has been applied in engineering structures for many years and could substitute the rebars in slabs or shells to some extent. Ceramsite concrete possesses several excellent properties, such as excellent heat-insulation and fire resistance; its dry density is approximately 2/3-1/5 of ordinary concrete, and its thermal conductivity is about half. In this study, the polystyrene foam insulation layer and the TRC webs as shear connectors were set between two face plates. TRC webs guarantee the essential stiffness and strength required for shear transfer, and greatly consolidate the cooperation between the face plates and even can attain the full composite possibly. The tests pertaining to the axial and flexural working behaviors under the vertical and transverse loading were carried out. The bearing capacity, failure features and deformations of TRCCP were discussed, which were compared with the evaluations from non-linear FEM analysis and analytic method with reference to [34]. This study aims to explore the failure modes and bearing capacity of the TRCCP subjected to axial 


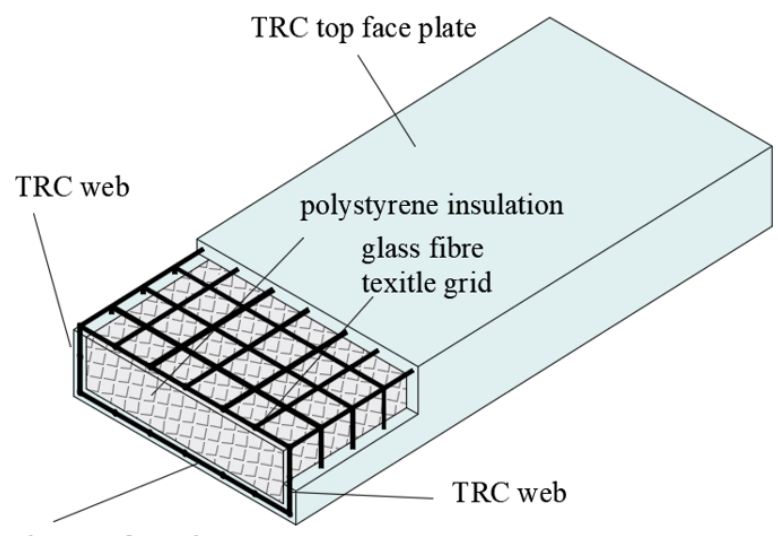

TRC bottom face plate

Figure 1: Schematic of TRCCP

and transverse load, which can provide reference for actual engineering application.

\section{Materials}

\subsection{Reinforced Materials}

In this study, bi-directional GFTG (grid mesh size: $25.4 \mathrm{~mm} \times$ $25.4 \mathrm{~mm}$, clear mesh size: $22.0 \mathrm{~mm} \times 21.0 \mathrm{~mm}$ ) was employed as the reinforced material, and steel wire mesh (SWM mesh size: $20.0 \mathrm{~mm} \times 20.0 \mathrm{~mm}$ ) was adopted as the reference strengthened material, as shown in Figure 2. GFTG yarn, a sort of composite material, is composed of fibers and resin; the yarn constitution depends on the material modulus and volume ratio, which implies that if all constituent materials are independent and noninteracting, the relevant composite-material theorem should correspond to the calculation of the elastic modulus of the textile warp and weft. Practically, the interaction between fibers and other materials such as the coating resin inevitably considerably deteriorates the mechanical properties of yarn, such as its modulus and tensile strength. Thus, the parameters of reinforced materials used in this paper study were tested experimentally, as presented in Table 1; the tests included those pertaining to the fineness of the fiber bundle [35], yarn tension [36] and wire tension [37].

\subsection{Ceramsite Concrete}

Structural lightweight aggregate concrete, which provides functions of both insulation and structure as adopted. The size of textile grid, penetration, flowability and water demand of concrete should be considered comprehensively;
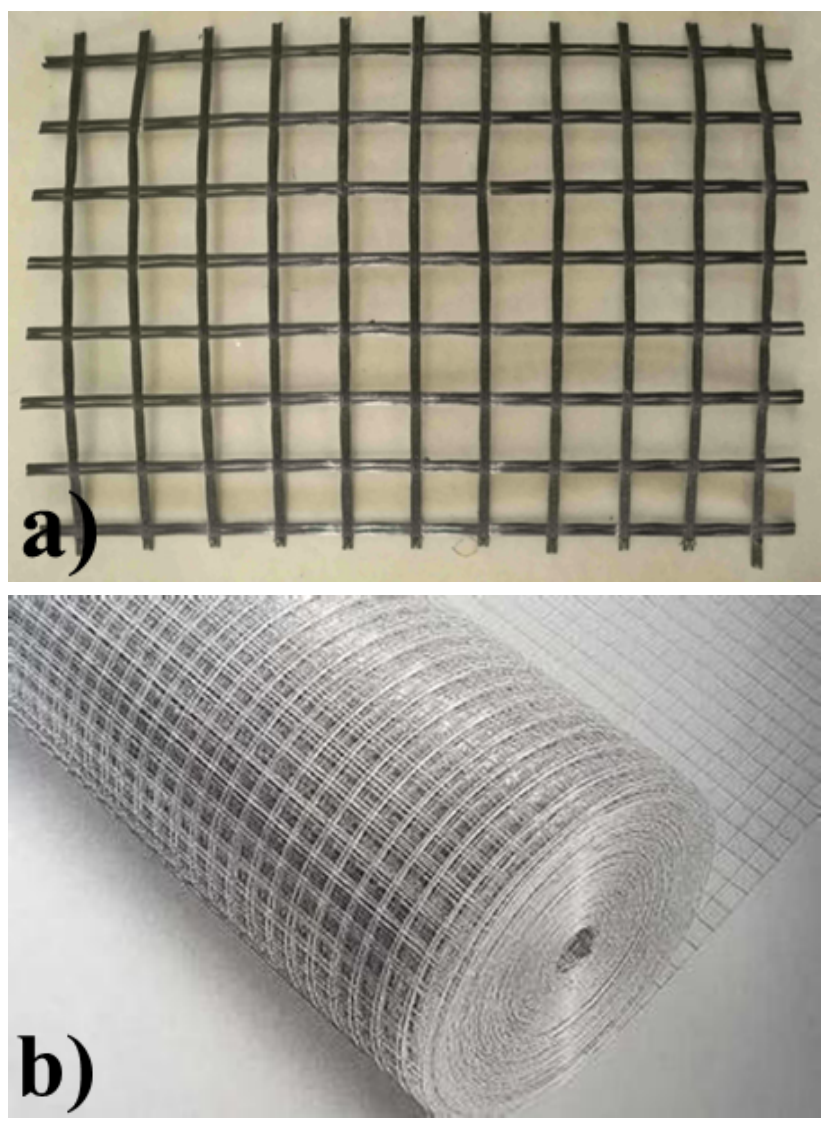

Figure 2: Reinforced materials: (a) Glass fiber textile grid and (b) Steel wire mesh

Table 1: Properties of reinforced materials

\begin{tabular}{cccc}
\hline Parameter & \multicolumn{2}{c}{ GFTG } & Steel \\
\cline { 2 - 3 } & warp & weft & wire \\
\hline Area $\left(\mathrm{mm}^{2}\right)$ & 1.02 & 1.02 & 0.49 \\
Modulus $(\mathrm{GPa})$ & 66.67 & 67.33 & 114 \\
Tension strength (MPa) & 1231.71 & 1109.71 & 846.7 \\
Ultimate elongation (\%) & 2.37 & 2.35 & 1.15 \\
Density/bundle/inch & 1 & 1 & 1.25 \\
\hline
\end{tabular}

thus, lytag aggregates within a maximum diameter of 5 $\mathrm{mm}$ were adopted. The concrete constituents used in the experiment are listed in Table 2, Portland cement is composed of four oxides: calcium oxide ( $\mathrm{CaO})$, silicon dioxide $\left(\mathrm{SiO}_{2}\right)$, aluminum oxide $\left(\mathrm{Al}_{2} \mathrm{O}_{3}\right)$ and iron oxide $\left(\mathrm{Fe}_{2} \mathrm{O}_{3}\right)$. The total amount of these four oxides accounts for $95 \%$ in clinker, and the mixture design is defined in Table 3. The compressive strength and elastic modulus were determined by performing tests on specimens according to ASTM C39/C39M [38]. The mechanical performances of concrete are summarized in Table 4. 
Table 2: Concrete raw material

\begin{tabular}{lccc}
\hline $\begin{array}{l}\text { Portland } \\
\text { cement }\end{array}$ & Fly ash & $\begin{array}{c}\text { Lytag aggregate } \\
\text { (within } 5 \mathrm{~mm} \text { diam.) }\end{array}$ & $\begin{array}{c}\text { Water } \\
\text { reducing } \\
\text { agent }\end{array}$ \\
\hline $\begin{array}{c}\text { Strength } \\
\text { grade: }\end{array}$ & Bulk packing density: $830 \mathrm{~kg} / \mathrm{m}^{3}$ & $\begin{array}{c}\text { Wesidue in sieve ration: } 5 \mathrm{~mm}-0 \%, \\
\text { Ju-II }\end{array}$ & Plain tap \\
P42.5 & Apparent density: $2300 \mathrm{~kg} / \mathrm{m}^{3}$ & $0.63 \mathrm{~mm}-66.8 \%, 0.16 \mathrm{~mm}-97.1 \%$ & water \\
& & Moisture content: $14.1 \%$ & \\
\hline
\end{tabular}

Table 3: Mixture design of ceramsite concrete $\left(\mathrm{kg} / \mathrm{m}^{3}\right)$

\begin{tabular}{cccccc}
\hline Cement content & Fly-ash content & Net water content & $\begin{array}{c}\text { Water reducing } \\
\text { agent }\end{array}$ & $\begin{array}{c}\text { Ceramsite } \\
\text { content }\end{array}$ & $\begin{array}{c}\text { Sand } \\
\text { content }\end{array}$ \\
\hline 280 & 70 & 182 & 10.4 & 422 & 346 \\
\hline
\end{tabular}

Note: * Water/cement ratio of 0.52 is used for concrete.

Table 4: Concrete mechanical indexes

\begin{tabular}{cccc}
$\begin{array}{c}\text { Axial } \\
\text { compressive } \\
\text { strength }(\mathrm{MPa})\end{array}$ & $\begin{array}{c}\text { Tensile } \\
\text { strength } \\
(\mathrm{MPa})\end{array}$ & $\begin{array}{c}\text { Elastic } \\
\text { modulus } \\
(\mathrm{GPa})\end{array}$ & $\begin{array}{c}\text { Dry apparent } \\
\text { density } \\
\left(\mathrm{kg} / \mathrm{m}^{3}\right)\end{array}$ \\
\hline 14.5 & 1.52 & 27.2 & 1163 \\
\hline
\end{tabular}

\subsection{Core Foam}

Polystyrene foam (EPS, density: $22 \mathrm{~kg} / \mathrm{m}^{3}$ ) was chosen as the core material of panel. Usually, the core in PCPs and NCPs functions as the key coordination material for face plates to transfer shear; however, in this study, the structural contribution of core foam is neglected, because of the presence of the continuous lightweight TRC web, whose stiffness is far higher than foam, even when rigid foam is applied.

\section{Experimental Program}

\subsection{Specimen Details}

The composite panel section is depicted in Figure 3. The inside corners of panels were designed to be arcs with a radius of $10 \mathrm{~mm}$ to reduce the stress concentration. SWM or GFTG as the reinforced material was simply placed in the middle of the face plates and webs. To avoid the complicated anchoring of the textile grid, approximately one plate-width GFTG was overlapped to utilize the bonding force between the fiber yarn and concrete, as shown in Figure $3 b$. For comparison, steel wire mesh reinforced-concrete

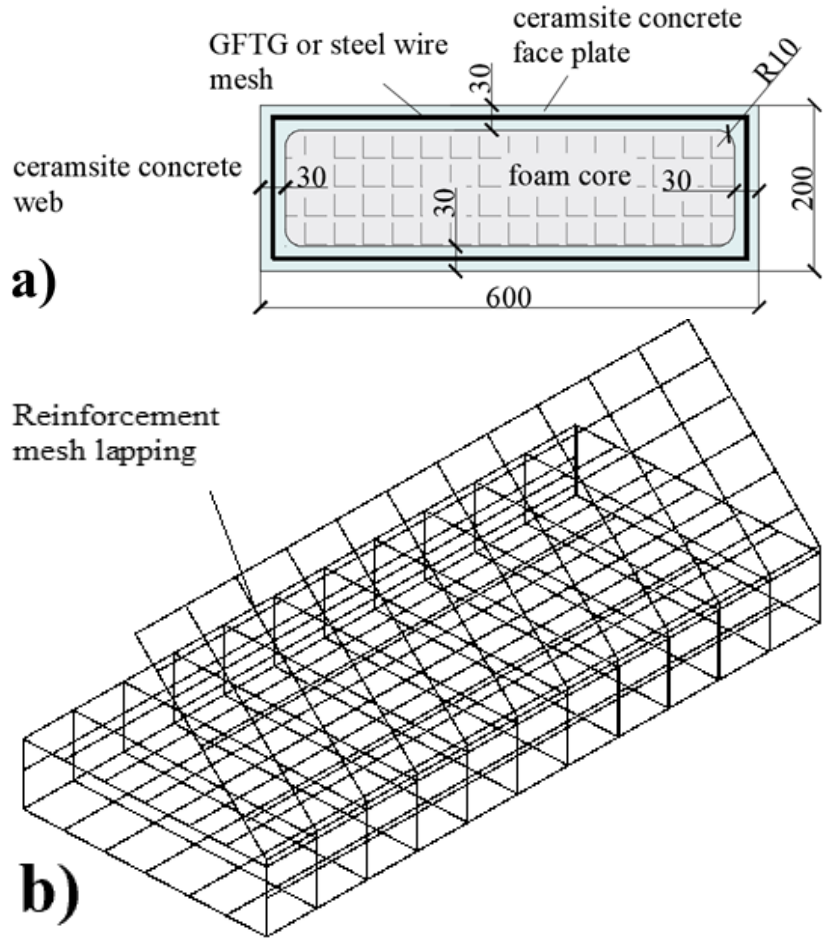

Figure 3: Sandwich panel section and reinforcement: (a) Section and (b) Reinforced material overlapping anchorage

composite panels (SMRCCP) specimens were produced in the same manner.

\subsection{Specimen Fabrication}

Polystyrene foam was served as the inner mold for casting concrete directly. However, because of its high softness, the surface of the foam was plastered with a layer of high 
strength mortar as a hard shell. After hardening, mortar lumps were stuck onto the shell surface to control the position of the GFTG or SWM. Subsequently, the GFTG or SWM was wrapped up outside the mortar lumps tightly and fixed temporarily on the surface. Next, as the core of the specimen, the entire unit was placed in the center of the mold to be poured over by concrete, vibrated until compaction and cured naturally. The main steps are shown in Figure 4.
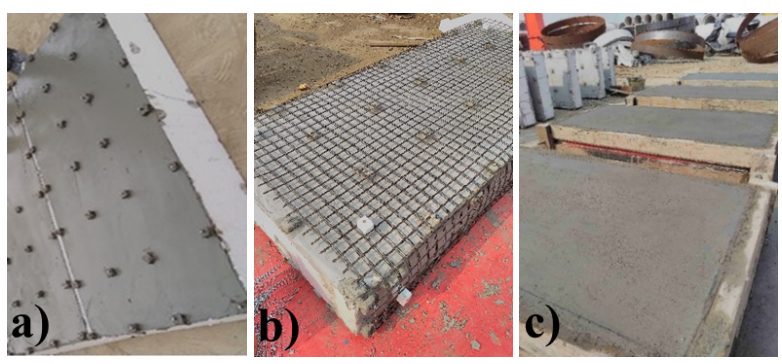

Figure 4: Main process for fabrication of panels: (a) high strength mortar layer with mortar lump; (b) wrapping with GFTG; and (c) casting concrete

\subsection{Experimental Scheme}

The test details are presented in Table 5. A single-layer reinforced material was set for withstanding tension at the bottom, and the overlapped double-layer was served as anchorage. Here, AL and TL refer to the axial and transverse loads respectively. The pseudo-static loading velocity was $0.5 \mathrm{~mm} / \mathrm{min}$ during the loading progress for the axial and transverse load tests.

Table 5: Specimen scheme

\begin{tabular}{cccc}
\hline Item & Specimen & $\begin{array}{c}\text { Reinforcement for } \\
\text { tension }\end{array}$ & Size $(\mathrm{m})$ \\
\hline AL & SCA1, SCA2 & SWM & $1.2 \times 0.6 \times 0.2$ \\
& FCA1, FCA2 & GFTG & $(1 \times W \times h)$ \\
TL & SCB1, SCB2 & Single-layer SWM & \\
& FCB1, FCB2 & Single-layer GFTG & \\
\hline
\end{tabular}

The axial load test scheme is shown in Figure 5. The geometric imperfections of panel ends were repaired with high strength mortar to ensure uniform stress. A steel hat and boot with both a thickness of $20 \mathrm{~mm}$ were placed at both ends for well-distributed axial force. The connections among the loading frame, actuator and load plate were spherical hinges. Steel bolts were used between the test

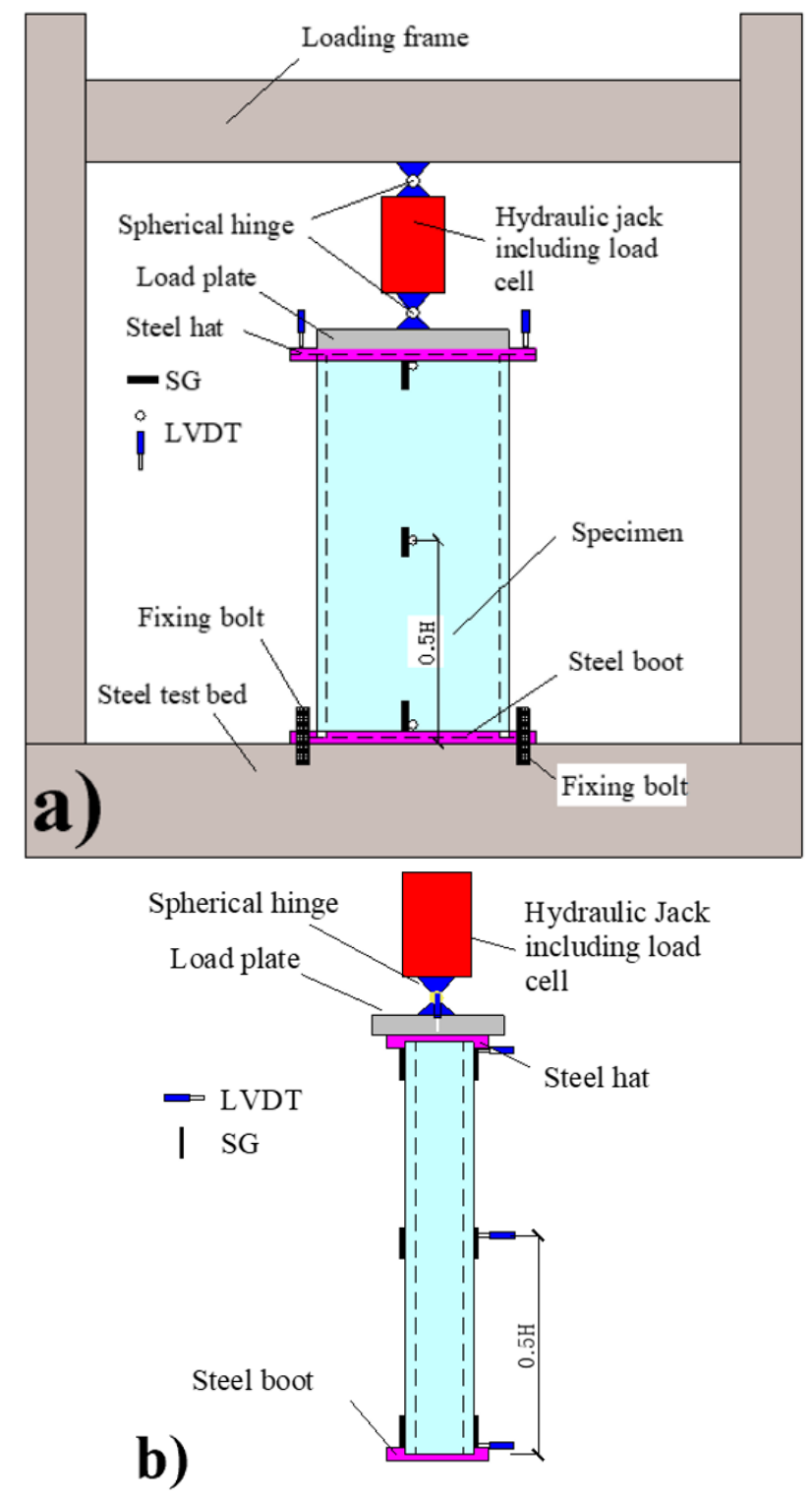

Figure 5: Axial load test scheme: (a) front view and (b) side view

bed and steel boot. Three units of strain gauges (SGs) were set on each plate surface along the axial direction at the top, middle, and bottom. Five linear variable differential transformers (LVDTs) were set up to monitor the panel's displacement: two for the vertical displacement of the top end, and three for the lateral displacements of the top, middle, and bottom correspondingly. It should be noted that in this study, just mean values of the two top LVDTs were on behalf of vertical displacements. To obtain the sheer panel displacements, the top and bottom lateral LVDTs were attached to the edges of the steel hat and boot, very close to the actual top and bottom shifts, so that the displacements of the steel hat and boot themselves could be excluded. 
The four-point transverse-load scheme is shown in Figure 6. Four LVDTs were installed to monitor the vertical displacement of specimens: one for the bottom-plate vertical deflection; and three for the top plate vertical displacements, among which one corresponded to the top deflection, and the other two pertained to the corresponding support sites. The load-displacement data were recorded by a universal test machine with the capacity of $5000 \mathrm{kN}$.
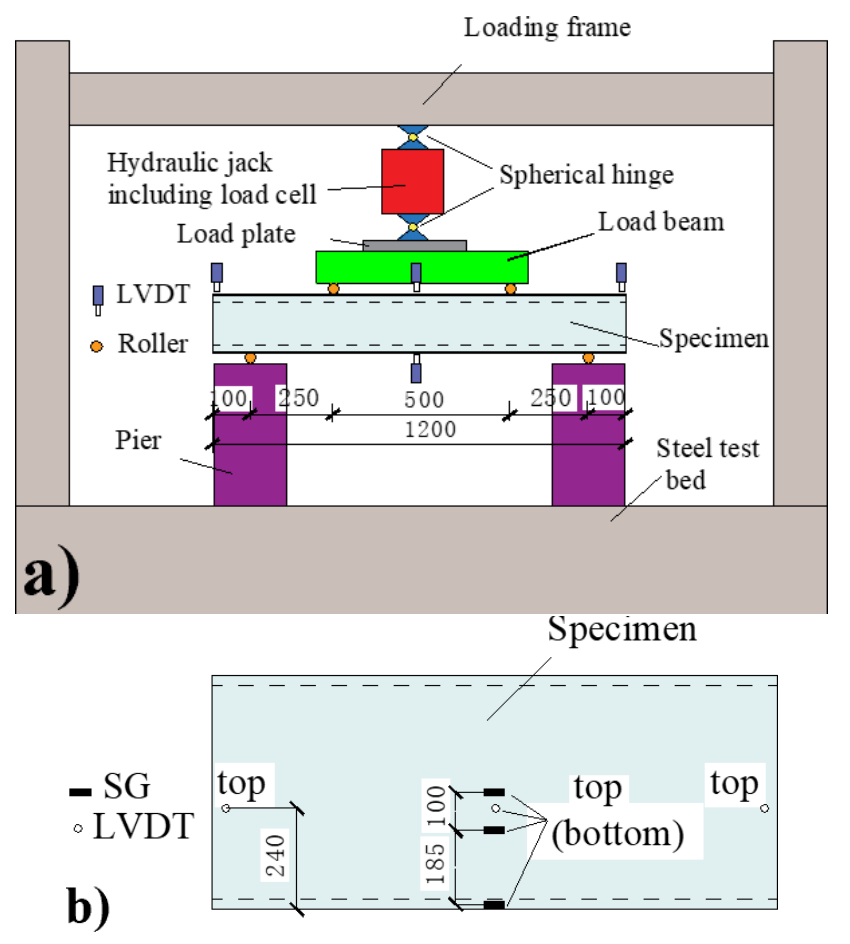

Figure 6: Transverse loading scheme: (a) front view and (b) side view

\section{Test Results}

\subsection{Axial Test}

The failure modes, load versus vertical and lateral displacement (L-D) curves, and load versus two-face-plate vertical strain (L-S) curves for SCA1, SCA2, FCA1, and FCA2 under axial load are presented in Figures 7-12. In terms of face-plate test strains, all the face plates were under pressure. The failure modes of SCA and FCA specimens are summarized in Table 6. The lateral top-end displacements of the panels in response to ultimate load (UL) are shown in Table 7, where $e$ is the lateral displacement of the top end and $h$ is the specimen thickness $(200 \mathrm{~mm})$. Although the lateral dis- placements at the top and middle sections were larger than those for the bottom, as shown in Figures 7-12, all the lateral displacements are nearly negligible, and the extra eccentricities due to the axial load can be elided. Considering the extremely low lateral end displacements, the boundary of both the panel-ends can be regarded as simply-supported. Table 8 presents that the key characteristic loads during the axial-load testing process and the corresponding vertical displacements until the ultimate breaking point is reached.

The same type of L-D curves demonstrated similar features. The vertical top L-D curves of the panel are selected for the subsequent discussion pertaining to curve features; the characteristic load points are labeled as uppercase letters A-D in Figures 7-12. At the inception, all the measuredpoint displacements increase linearly with the load augmentation; next, point A accompanied by a low sound, corresponds to the first deviation load; subsequently, the L-D curves vary with irregular fluctuation. Generally the lateral displacements reverse against the initial state from A to B, which could lead to crossing of the origin point and change the sign of the displacement in the figure; an inflec-
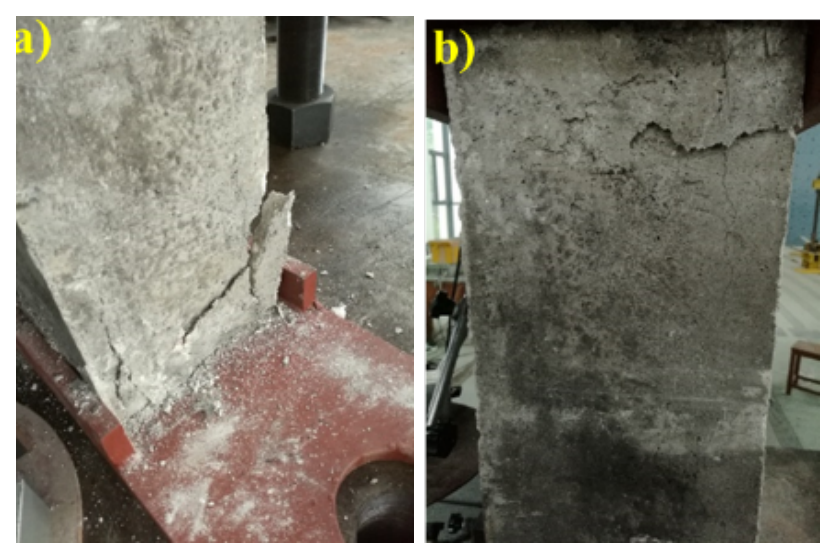

Figure 7: SCA1 failure modes: (a) concrete crushing at the bottom and (b) concrete crushing at the top
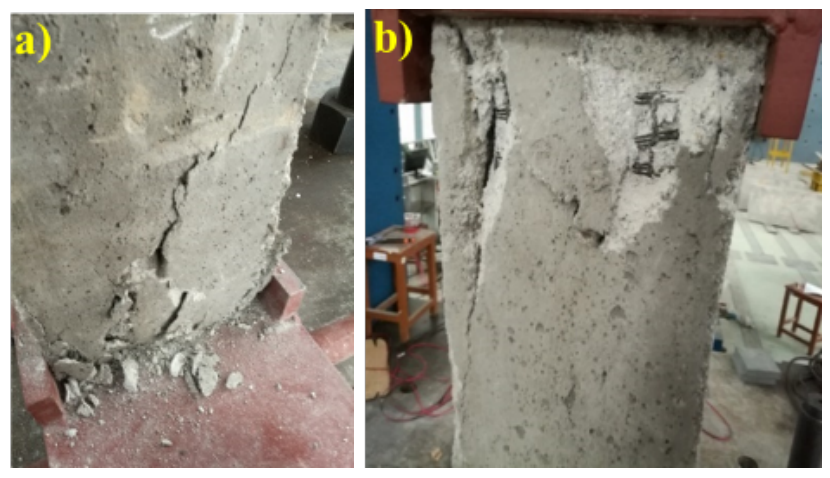

Figure 8: FCA1 failure modes: (a) concrete crushing at the bottom and (b) concrete crushing at the top 
Table 6: Experimental results

\begin{tabular}{|c|c|c|}
\hline Item & Specimen & Failure modes \\
\hline \multirow[t]{4}{*}{$\mathrm{AL}$} & SCA1 & Concrete crush at the top and bottom ends \\
\hline & SCA2 & Long cracks at the top, partial concrete crush \\
\hline & FCA1 & Concrete crush at the top and bottom ends \\
\hline & FCA2 & Concrete crush at the top and bottom ends \\
\hline \multirow[t]{4}{*}{ TL } & SCB2 & $\begin{array}{l}\text { Flexural crack throughout the whole bottom plate near one loading-beam support and extending } \\
\text { to the lateral side; broken wire at the bottom of the web }\end{array}$ \\
\hline & SCB2 & $\begin{array}{l}\text { Flexural cracks throughout the whole bottom plate and extending to the lateral side; broken wire } \\
\text { at the bottom of the web }\end{array}$ \\
\hline & FCB1 & $\begin{array}{l}\text { Inclined flexural-shear crack throughout the whole bottom between loading-beam support and } \\
\text { panel support; broken yarn at the bottom of the web }\end{array}$ \\
\hline & FCB2 & $\begin{array}{l}\text { Inclined cracks throughout the whole bottom between loading-beam support and panel support } \\
\text { influenced mainly by flexure and shear partially by shear; broken yarn at the bottom of the web }\end{array}$ \\
\hline
\end{tabular}

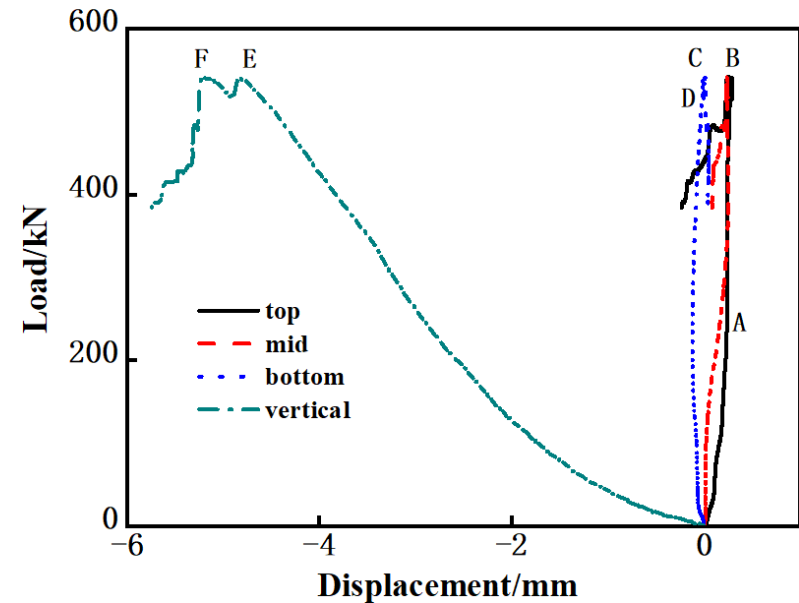

(a)

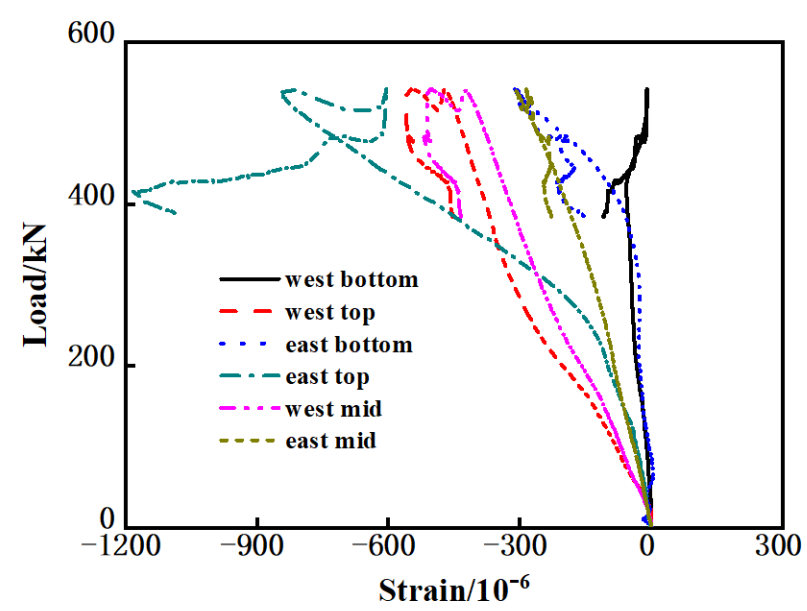

(b)

Figure 9: Load-displacement and strain curves for SCA1: (a) loaddisplacement curves, (b) load-strain curves

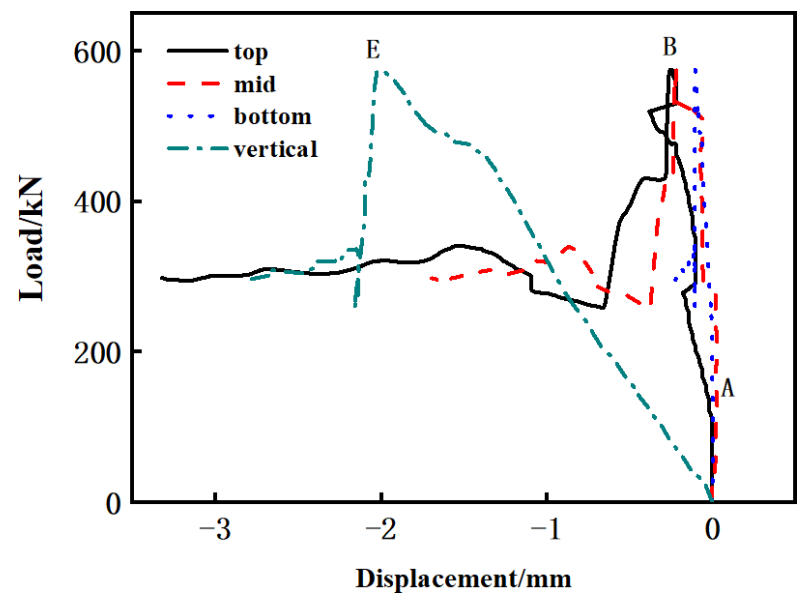

(a)

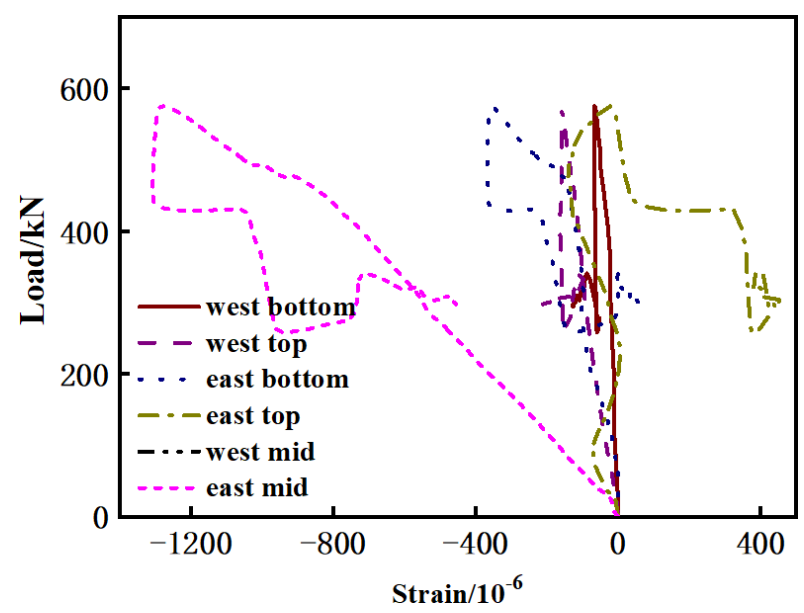

(b)

Figure 10: Load-displacement and strain curves for SCA2: (a) loaddisplacement curves, (b) load-strain curves 


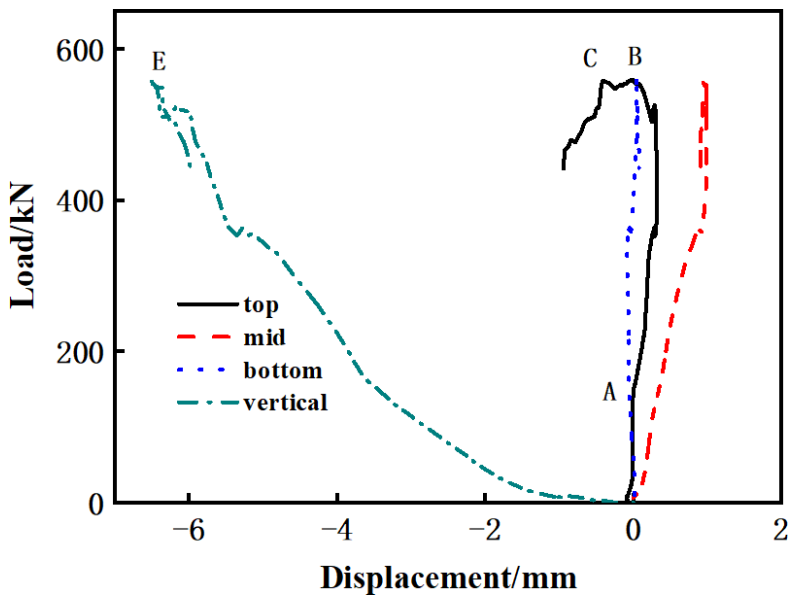

(a)

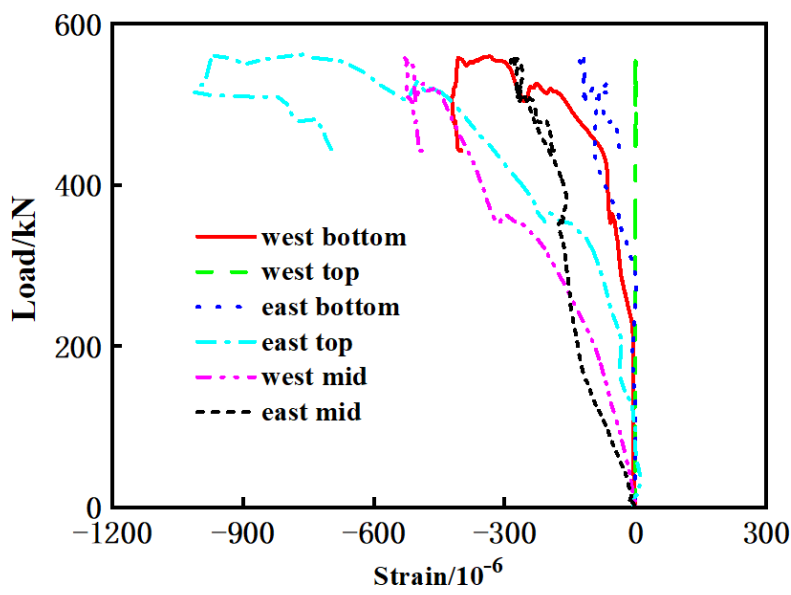

(b)

Figure 11: Load-displacement and strain curves for FCA1 (a) loaddisplacement curves, (b) load-strain curves

tion point even occur in some cases. Before the UL reached point B or E, short plateaus are included in partial curves, in which the displacements increase while the loads are constant until point C, D or F. For loads to the UL, the panels lose their bearing capacities suddenly at point $C$ with a loud sound, and the curve fluctuation strongly; in these cases, the ductility is not significant and points $\mathrm{C}$ and $\mathrm{F}$ may even be non-existent.

As shown in Table 6 and Table 8, the failure modes and ultimate bearing capacity of SCA were almost identical to those of FCA. Significant concrete crushing at the top and bottom ends along with some vertical cracks, was noted, while the specimen ductility was not conspicuous. Although the deformation capacity of glass fiber textile was considerably larger than that of steel wire, the experimental deformation of specimens (both SCA and FCA) was controlled by the concrete, not the reinforced-material elongation deformability on the condition of axial pressure.

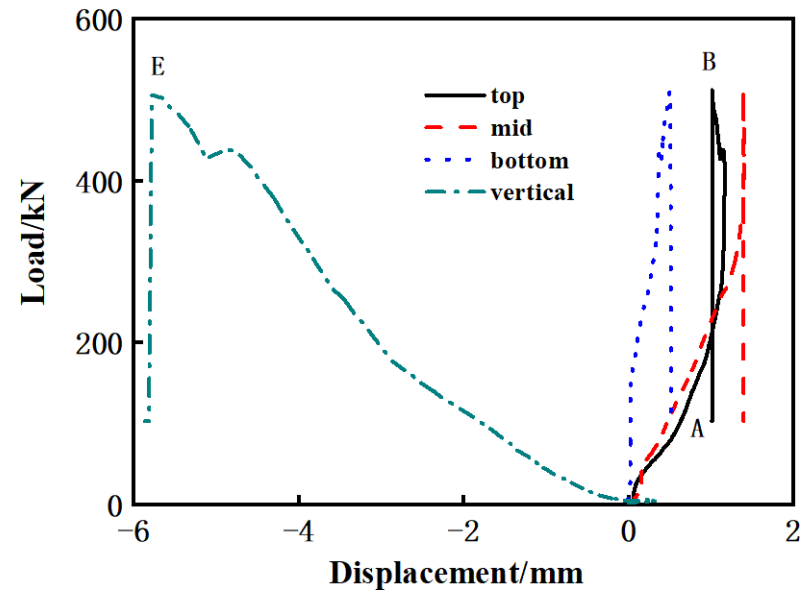

(a)

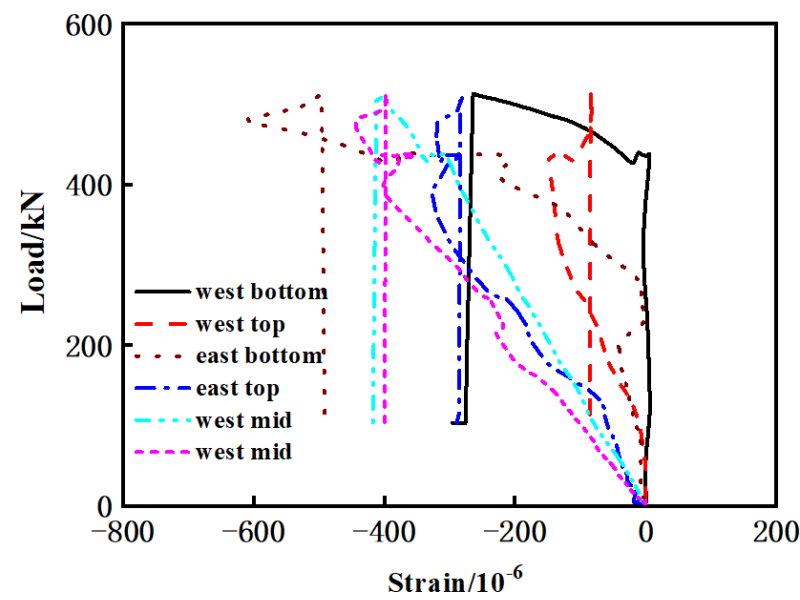

(b)

Figure 12: Load-displacement and strain curves for FCA2: (a) loaddisplacement curves, (b) load-strain curves

Table 7: Top point displacement under axial load

\begin{tabular}{ccccc}
\hline $\begin{array}{c}\text { Specimen } \\
\text { number }\end{array}$ & SCA2 & SCA3 & FCA1 & FCA3 \\
\hline $\mathrm{e} / \mathrm{mm}$ & 0.59 & 0.15 & 0.12 & 0.51 \\
$\mathrm{e} / \mathrm{h}$ & 0.00295 & 0.00075 & 0.0006 & 0.00255 \\
\hline
\end{tabular}

Table 8: Characteristic load and UL displacement for axial test

\begin{tabular}{|c|c|c|c|c|}
\hline \multirow[t]{2}{*}{ Item } & \multirow[t]{2}{*}{ Specimen } & \multicolumn{2}{|c|}{$\begin{array}{c}\text { Characteristic } \\
\text { load }(\mathrm{kN})\end{array}$} & \multirow{2}{*}{$\begin{array}{c}\text { Displacement } \\
(\mathrm{m}) \\
\text { Failure }\end{array}$} \\
\hline & & FSL & UL & \\
\hline \multirow[t]{4}{*}{$\overline{A L}$} & SCA1 & 255.0 & 542.0 & 2.6 \\
\hline & SCA2 & 120.6 & 575.6 & 2.0 \\
\hline & FCA1 & 146.7 & 559.2 & 3.3 \\
\hline & FCA2 & 109.8 & 512.0 & 2.9 \\
\hline
\end{tabular}




\subsection{Transverse Test}

Figure 13 shows the failure modes, and Figures 14-15 show load vs. midpoint deflection (L-MD) and L-S curves of the SCB and FCB specimens under the transverse load. The bottom midpoint deflections are marked considering the characteristic points with the uppercase letters $\mathrm{A}, \mathrm{B}$, and C for the succeeding discussion. Before A, the L-MD curves of the top and bottom midpoint are almost linear with their slopes decreasing slightly. After A, which corresponds to the first deviation load, the L-MD curves decline rapidly and fluctuate with a crackling sound till the maximum UL at load point B. Next, the load dwindles with the further deflection, and the panels collapse and lose their bearing capacities at C. It should be noted that the L-MD curve of SCB1 demonstrates a strong violation stage significantly between $\mathrm{B}$ and $\mathrm{C}$, owing to the partial steel wire fracture occurring in batches. From 0 to A, the face-plate displacements exhibit a trend of slight reversal. Before point $C$, all panels exhibit obvious nonlinear deformations. Most cracks were perpendicular to the bottom edges of specimens; however, a few cracks were slightly tilted, extending across the entire bottom plate and up to most of the height along the side webs. After the influence from the top plate-end rigid-body displacements is eliminated, the deflections of the bottom are much larger than those of the face. SCB and FCB both exhibit excellent cooperation between webs and face plates, as shown in Figure 15.

In summary, the main failure modes under the transverse four-point load were wide flexural cracks and broken wires and yarns at the bottom of the web, mingled with certain traits of shear failure. But no evident concrete crushing, spalling, or overlapping-area pull-out occurred. As textileyarn elastic modulus is far lower than that of steel wire, the deflections of FCBs were larger than those of SCBs. FCB exhibits sufficient bearing capacity more than that of $\mathrm{SCB}$ overall. The ductility of FCB was approximately 2-3 times that of SCB, even though it was a type of pseudo-ductile. Table 9 presents that the ultimate loads and maximum displacements under transverse load test.

Table 9: Characteristic load and displacement

\begin{tabular}{lccccc}
\hline Specimen & UL & \multicolumn{4}{c}{ Displacement $(\mathrm{mm})$} \\
& & \multicolumn{2}{c}{ Yielding } & \multicolumn{2}{c}{ Failure } \\
& & Face & Bottom & Face & Bottom \\
\hline SCB1 & 19.1 & -0.08 & 0.28 & 1.27 & 2.57 \\
SCB2 & 21.3 & 0.04 & 0.39 & 1.40 & 2.20 \\
FCB1 & 25.0 & 0.45 & 0.47 & 2.27 & 5.10 \\
FCB2 & 33.5 & 0.10 & 3.90 & 2.98 & 5.73 \\
\hline
\end{tabular}
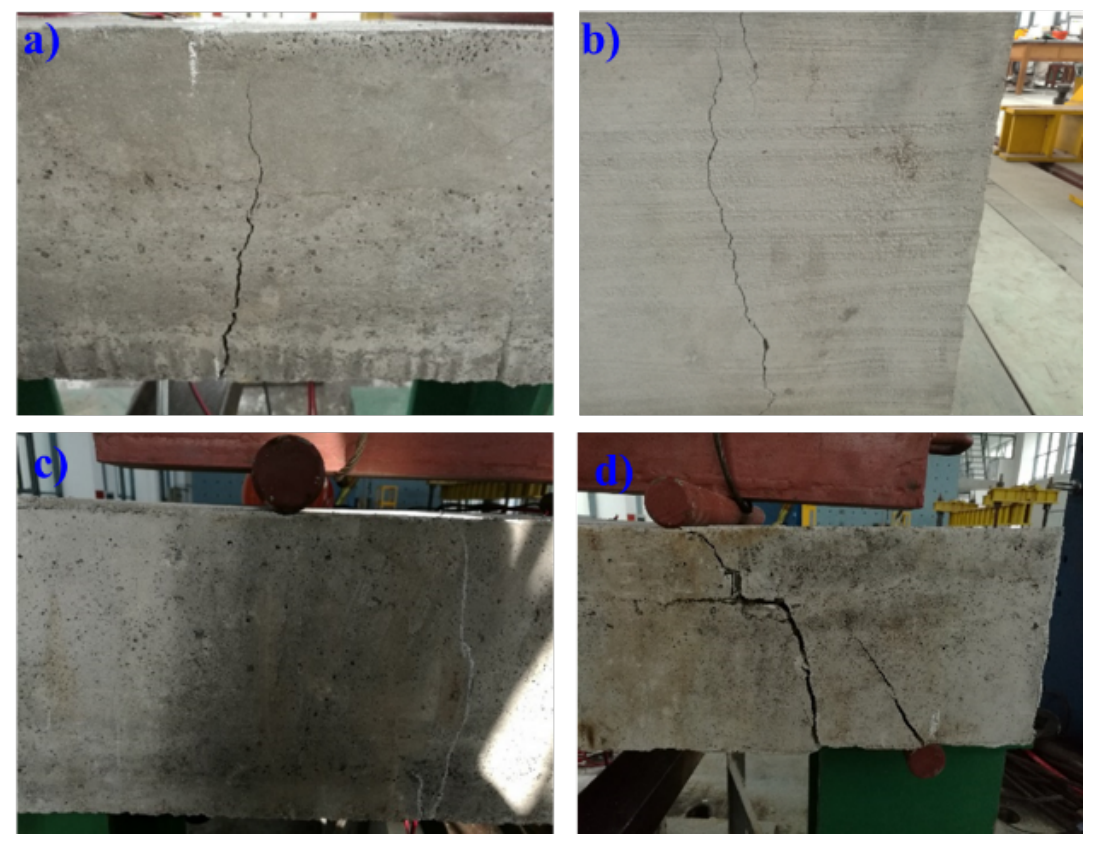

Figure 13: Transverse test failure: (a) side crack in SCB1; (b) continuous crack in SCB1 bottom; (c) side crack in FCB1; and (d) side flexuralsheared joint crack in FCB2 


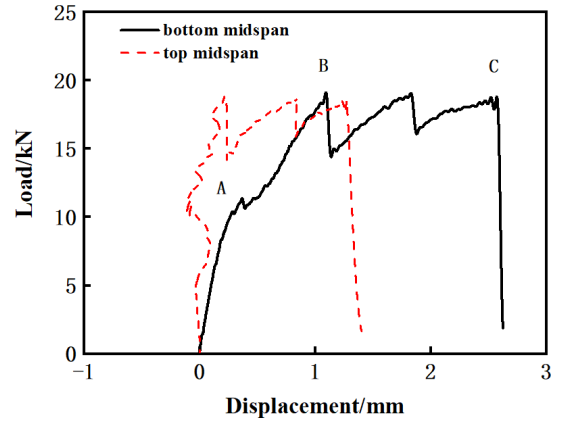

(a)

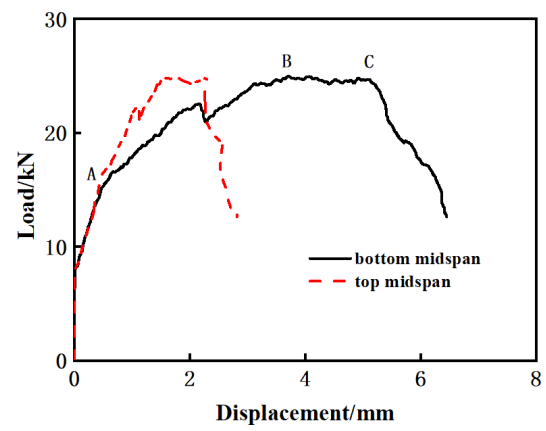

(c)

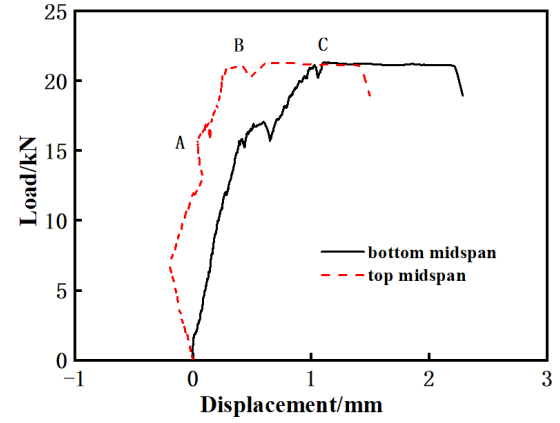

(b)

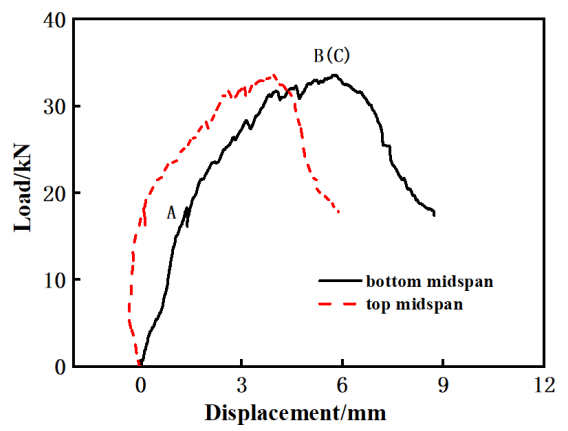

(d)

Figure 14: Load-deflection curves: (a) SCB1; (b) SCB2; (c) FCB1; and (d) FCB2

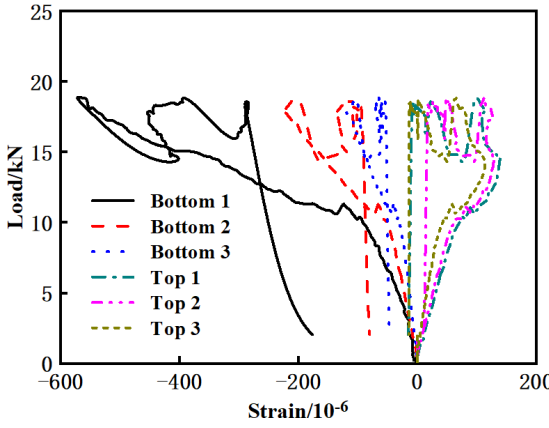

(a)

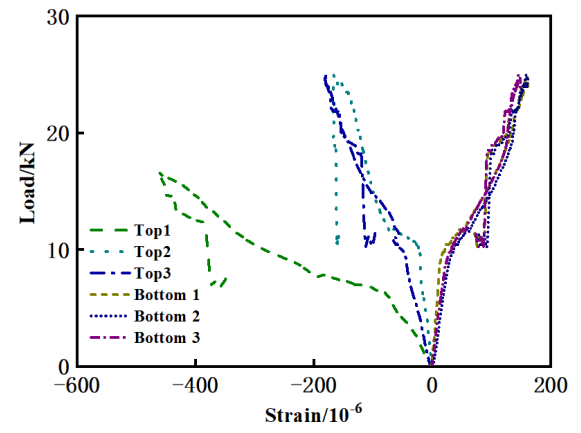

(c)

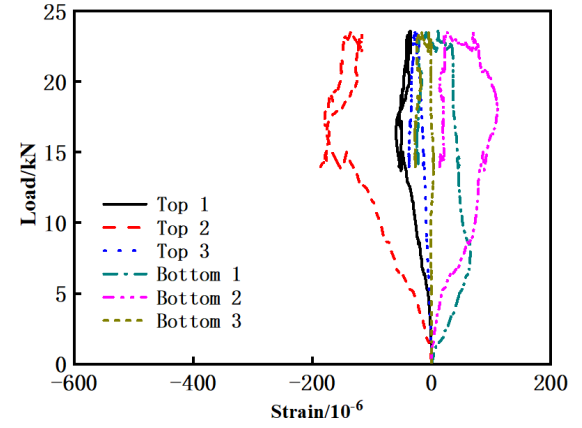

(b)

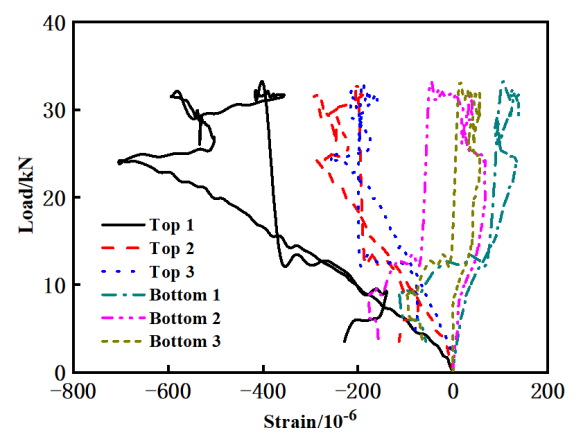

(d)

Figure 15: Load-strain curves: (a) SCB1; (b) SCB2; (c) FCB1; (d) FCB2 


\section{Analysis Method}

\subsection{Finite Element Analysis}

Finite element analysis is a powerful method to simulate the nonlinear behavior of concrete members subjected to all types of load actions. ANSYS software was employed to simulate the loading process on TRCCP with numerical model referred to the abovementioned working conditions. Solid65 element was utilized for concrete, and Link180 was used for steel wire and textile yarn. The element mesh sizes were controlled to match the actual sizes of actual wire and textile, and each element node had three translational degrees of freedom. The boundary conditions were simplysupported. To circumvent the unnecessary calculation divergence, the panel materials, except for polystyrene foam, were considered to be nonlinear during the loading process. Elements' sizes were $15 \mathrm{~mm} \sim 30 \mathrm{~mm}$. Hongestad constitutive model and multilinear kinematic hardening rule were adopted for concrete, while bilinear kinematic hardening rule was used for steel wire. Linear-elastic model was used for core foam, whose structural action was neglected because its stiffness and strength capacity were an orderof-magnitude lower than those of concrete, steel wire and GFRP.

\subsection{Analysis Method}

TRCCP that is highly similar to the traditional RC slab in possess of the RC webs, similar to steel bars, GFRP can withstand higher tensile stress and can have higher adhesion to concrete, fortifies the cooperation between the two face plates and attains full composite in structure formation. Thus, it's expected that analytic method under RC theory can be introduced to estimate TRCCP performance. On the basis of the abovementioned experiments, axial and flexural carrying capacities are discussed, while the shear capacity is excluded because of no occurrence of shearing failure phenomena. The simplified section model for panel

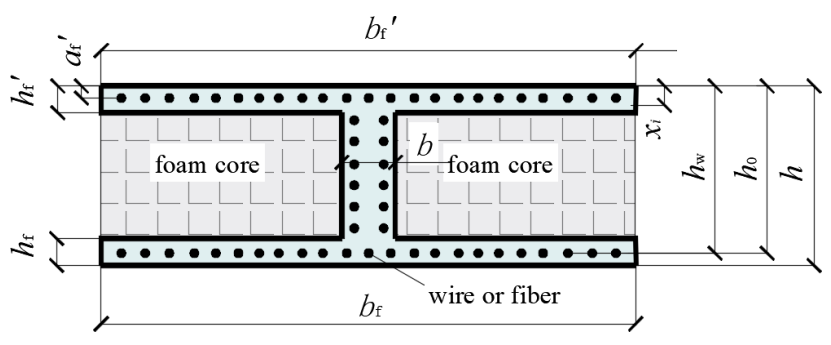

Figure 16: Simplified section of TRCCP for calculation calculation is shown in Figure 16, in which the two side webs are combined into one middle theoretical web.

\subsubsection{Basic Assumptions}

Basic assumptions in the following analysis were adopted as below:

(1) A plane section of the member remains a plane from the start of loading to failure, regardless of the compression or tension zone of section.

(2) The deformation of the member is sufficiently small even under the ultimate states.

(3) The concrete cannot bear tension, and SWM \& GFTG cannot withstand compression.

(4) The steel wire and GFTG yarn are elastic according to the material tests. If no specific explanation is provided, Standard-value-of-strength (SVS) material strength is used for the calculation.

(5) The core foam does not contribute structurally and acts only as a hypothetical thermal insulation layer because its elastic modulus is extremely lower than that of concrete, steel wire, and GFRP textile.

\subsubsection{Calculation Axial Compression}

The ultimate bearing capacity for axial compression is referenced [34],

$$
N_{u}=\varphi f_{c} A_{c}
$$

where $\varphi$ is stability factor according to slenderness ratio; here, for a two-end simply supported case, its value is 0.95 ; $f_{c}$ is axial compressive strength; $A_{c}$ is gross concrete section area including the GFRP area because of its extremely small value.

\subsubsection{Calculation for Transverse Bending}

The equivalent depth, $x$, of the compressive zone and the ultimate moment can be calculated with [34]:

$$
\begin{gathered}
\alpha_{1} f_{c} \beta_{1} b x=\sum \sigma_{f} A_{f} \\
M=\alpha_{1} f_{c} \beta_{1} b_{f}^{\prime} \chi\left(d-\frac{x}{2}\right)
\end{gathered}
$$

where $x$ is equivalent depth of compressive zone, $\beta_{1} c$ does not exceed the depth of compression flange, $c$ is the distance from extreme compression fiber to neutral axis; only 
$x$ in the compression flange is discussed here, because all cracks' tip penetrated the compression flange at the ultimate limit stage. $M$ is moment; $\alpha_{1}$ is average stress ratio in rectangular compression block (1.1); $\beta_{1}$ is depth ratio in in rectangular compression block (0.75); $b$ is web width; $b_{f}^{\prime}$ is effective width of compression flange for computation; $d$ is distance from the extreme compression fiber to the centroid of longitudinal tension force; $\sigma_{f}$ is stress of steel wire or textile yarn;is area of steel wire or textile yarn.

For comparing the result of the experiments with FEM, the SVS material strength is used; thus, $x \leq x_{b}$, because nearly no yielding stress is present in the case of the steel wire and GFRP yarn.

Theoretically, when $x=x_{b}$,

$$
\sigma_{f} \leq f_{t b}
$$

where $x_{b}$ is balanced failure depth of compressive zone; $f_{t b}$ is ultimate strength due to lack of yielding point for steel wire and textile yarn, but $\sigma_{f}$ is far less than $f_{t b}$ actually.

The ultimate moment can be expressed as

$$
M_{u}=\frac{P_{u}}{2} l_{d}
$$

where $P_{u}$ is ultimate load; $l_{d}$ is length from the support to loading point $(250 \mathrm{~mm}) ; M_{u}$ is ultimate moment.

\section{Discussion for the results}

\subsection{Axial load}

The face-plate strain curves of specimens, shown in Figures 9-12, indicate that both sides of the test panels were under compression in most cases. Numerical analysis on the load-displacement responses of the sandwich panels was conducted through Finite Element (FE) modeling using software ANSYS. In such finite element model, composite, and core were modeled using Continuum 3-D, 8 node (C3D8R) solid element, and the nodes at the joint are coupled assuming no sliding between the composite materials and the core. Concentrated loading is applied on the model by defining the displacement on the loaded node. The boundary conditions are fixed at both ends. The FEM failure modes for both TRCCP and SMRCCP were material strength failure under a small slenderness ratio, as shown in Figure 17, wherein circles represent the damaged areas. All specimens failed due to concrete crushing and cracking at both panel ends in the FEM analysis, matching the actual test failure modes presented in Table 3 and Figures 7-8. Throughout the entire test process, GFTG could also constrain the concrete and maintain the cooperation of the

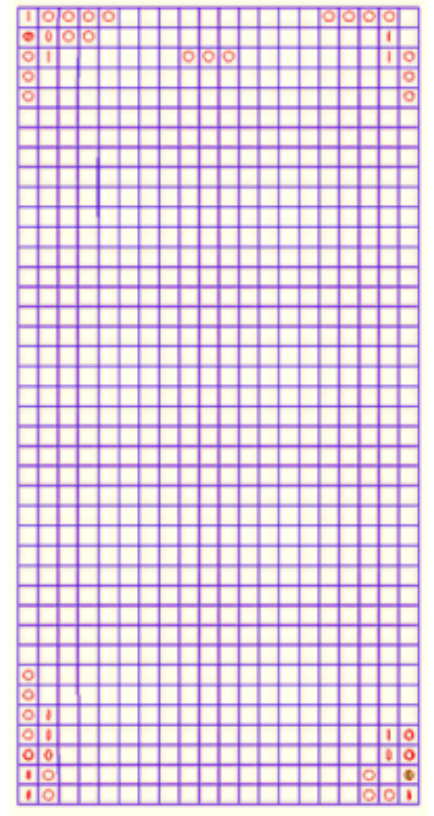

Figure 17: FEM failure for axial load

Table 10: Vertical ultimate bearing capacities

\begin{tabular}{cccc}
\hline Specimen & Tests $(\mathrm{kN})$ & \multicolumn{2}{c}{ Analysis results $(\mathrm{kN})$} \\
& & FEM & Analytic method \\
\hline SCA1 & 541.8 & 526.5 & \\
SCA2 & 575.6 & & 611.6 \\
FCA1 & 559.2 & 527.0 & $404.9(\mathrm{DSC})$ \\
FCA2 & 512.2 & & \\
\hline
\end{tabular}

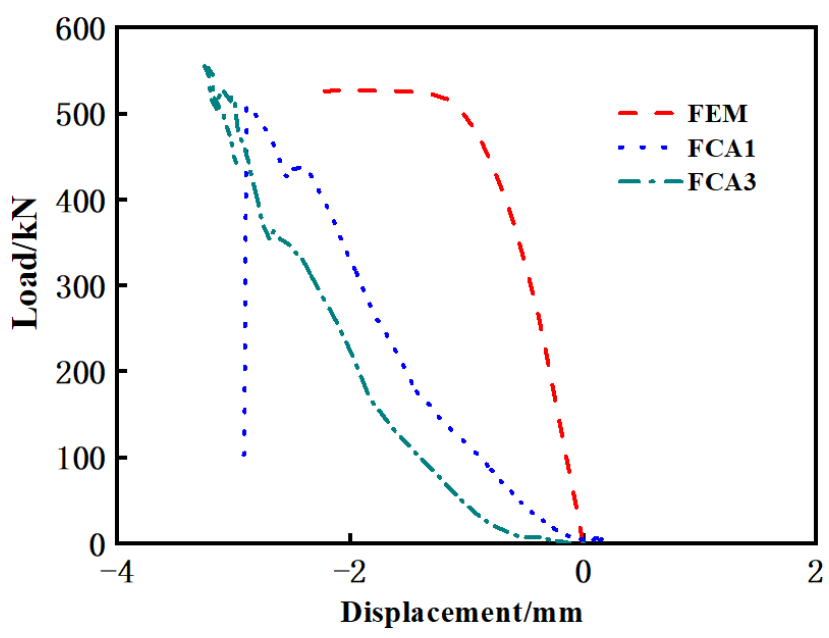

Figure 18: Axial UL vs. top vertical displacement for FCA

two face plates and integrity of the panel as similar to the SWM's function.

The axial UL of panels SCA1, SCA2, FCA1 and FCA2 obtained from experimental tests, FEM simulation and an- 
alytic results are presented in Table 10. Figure 18 depicts the axial load vs. vertical displacements for the FCAs, pertaining to the test and FEM results. The ULs predicted with experimental data of SCA1 SCA2 and FCA1 are higher than those with FEM by $2.9 \%, 9.3 \%$ and $6.1 \%$ respectively. However, the predicted UL for FCA2 is lower than that obtained from the analytical FEM model by $2.8 \%$. The results for the SMRCCP and TRCCP did not exhibit any substantial differences. The ULs obtained from the analytic method were higher than those from the experimental data by $22.4 \%$, $27.9 \%, 25.2 \%$ and $17.5 \%$, whereas if the design strength of concrete was adopted for comparison, the ULs obtained from analytic method were considerably lower than the test values and could be used to predict the ultimate bearing capacity directly after being fine-tuned. The FEM-obtained L-D curve in Figure 18 exhibits well-defined elastic and plastic stages; however, the curve pertaining to the tests does not exhibit notable yielding plateau and nonlinear stage, but is more analogous to nonlinear elastic behavior instead. The difference between the features of L-D curves obtained using FEM and tests imply that the initial vertical stiffness of specimens, as obtained from tests, is smaller than those obtained from FEM, probably due to the occurrence of the local crushing in advance on the end unevenness at the touching faces between the specimens and experimental set-up.

\subsection{Transverse load}

The FEM failures of SCB and FCB under transverse ultimate loads are shown in Figure 19. The element cracks surrounded the three faces of the panel, which were integrated with in the most height of two-side webs and the entire bottom plate. Among them, one or two key macro-cracks occurred, which extended to the top upper area of the web akin to the practical failure: a type of flexural failure. The FEM failure modes of TRCCP and SMRCCP were remarkably similar in general, which is due to the structures were dominated by flexural shearing failure, the failure load mainly depends on the shear strength of the new material and the flexural cracks near the load position matched with the experimental damage. However, some issues in the case of FEM should be noted: (a) The crack elements were dispersed within a certain width on the webs primarily due to the shear effect. (b) The crack elements at the SCB bottom plate were at a larger angle than those at the FCB plates due to the lower elastic modulus of GFTG yarn. (c) The ductile phase of FEM analysis is shorter than that in the experiment, which is a numeric divergence due to the con-
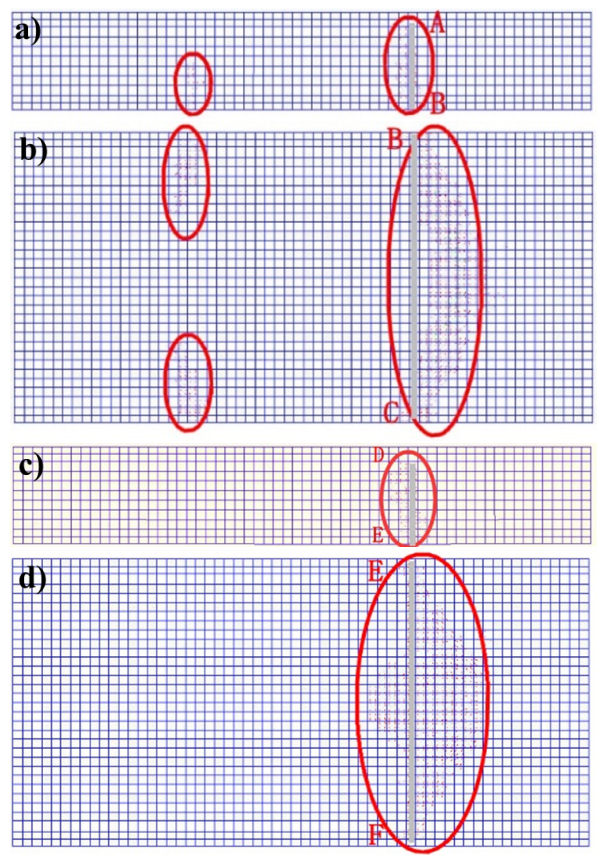

Figure 19: FEM failure of $S C B$ and $F C B$ under transverse load: (a) $S C B$ side; (b) SCB bottom; (c) FCB side; and (d) FCB bottom

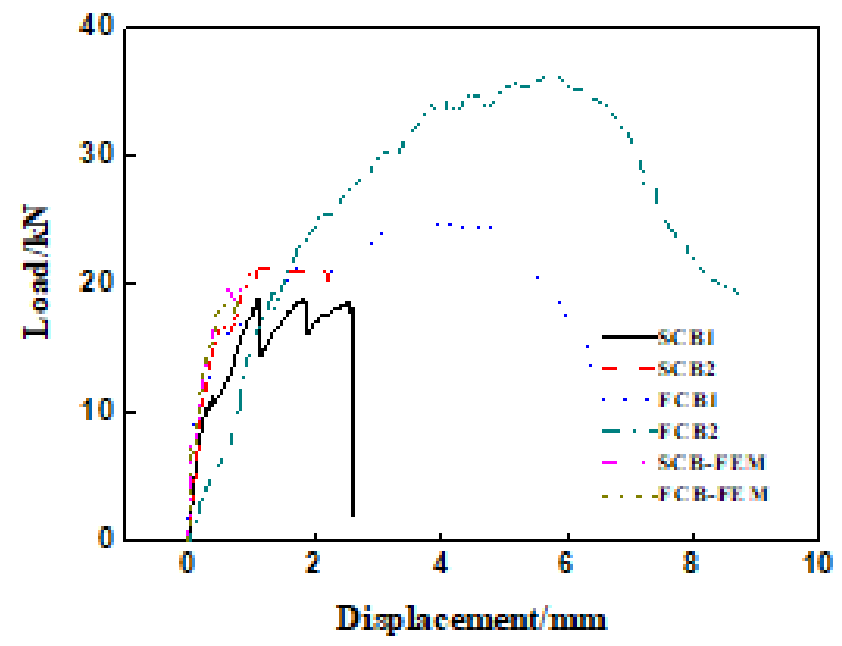

Figure 20: Bottom deflections and loads

siderably large displacement experienced during the strong nonlinear stage after cracking.

The relevant L-MD curves and ULs from experiments and FEM analysis are shown in Table 11 and Figure 20. The experimental curve for FCB1 displays self-evident intense load fluctuation at the nonlinear stage, while the corresponding ones for the others are not so strong. At the primary loading stage, the loads are correlated linearly with the displacements, and the experimental deflections are generally consistent with the FEM values. With load increasing continuously, the physical panel behaved clearly 
Table 11: Transverse ultimate load

\begin{tabular}{|c|c|c|c|c|}
\hline \multirow[t]{3}{*}{ Specimen } & \multirow[t]{3}{*}{ Test (kN) } & \multicolumn{3}{|c|}{ Flexural analysis results $(\mathrm{kN})$} \\
\hline & & \multirow[t]{2}{*}{ FEM } & \multicolumn{2}{|c|}{ Analytic method } \\
\hline & & & Concrete crushing & Reinforcement rupture \\
\hline SCB1 & 19.1 & 18.8 & $17.4\left(0.5 b_{f}^{\prime}, 1 h_{f}^{\prime}\right)$ & $15.4\left(1 b, 1 h_{f}^{\prime}\right)$ \\
\hline SCB2 & 21.3 & & $26.0\left(0.75 b_{f}^{\prime}, 1 h_{f}^{\prime}\right)$ & \\
\hline SFCB1 & 25.0 & 19.9 & $34.7\left(1 b_{f}^{\prime}, 1 h_{f}^{\prime}\right)$ & $24.7\left(0.5 b, 1 h_{f}^{\prime}\right)$ \\
\hline SFCB2 & 33.5 & & & $35.0\left(0.75 b, 1 h_{f}^{\prime}\right)$ \\
\hline
\end{tabular}

Note: ${ }^{\star} b_{f}$ and $h_{f}$ are the width and height of the compression flange respectively.

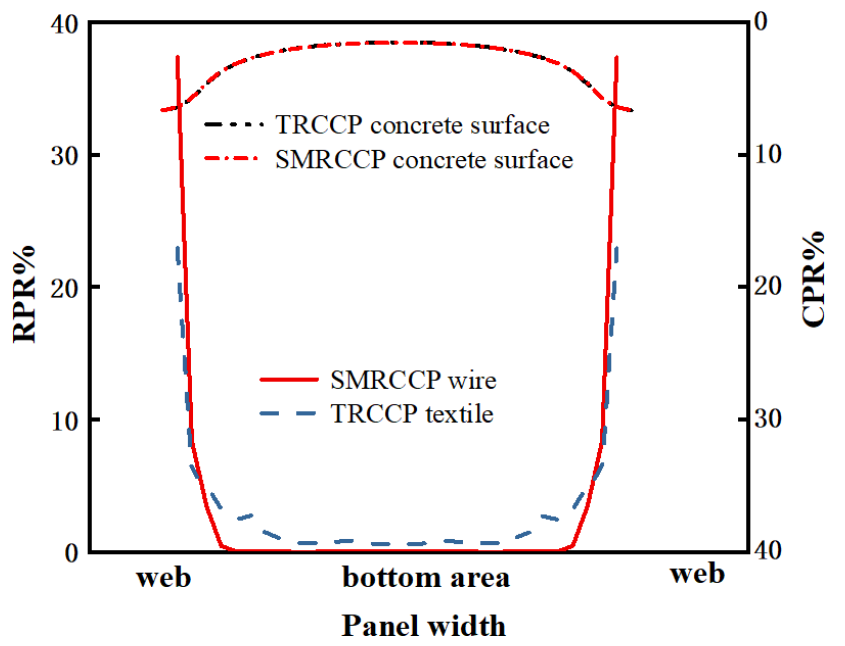

Figure 21: CPR and RPR distribution in the panel

nonlinearly and exhibited ductile deformation. However, this type of ductility is supposed to be pseudo ductility induced mainly by fiber yarn elongation, especially in the key crack area at the ultimate limit stage when GFTG is still at the elasticity phase. FEM analysis did not simulate the late part of the plateau or nonlinear increment well owing to the oversized translation resulting in numeric divergence. GFTG or SWM both ensured the panel integrity before and after ultimate failure.

It should be noticed that the SCB specimens lost their bearing capacity abruptly at the maximum loading, while FCB specimens exhibited a gradient. It can thus be deduced that some reinforced wires broke at the ultimate failure stage, yet fiber yarns did not, as their maximum stresses were considerably different from the tensile strength. Thus, the ultimate failure mode for FCB was controlled mainly by excessive displacement, which also hints at a non-uniform load effect occurring at the same cross section, a type of shear lag effect on the compressed flange of the concrete member and reinforcements.

To evaluate approximately the foregoing effective width within the width of flange, the participation ratios of the tensile flange reinforcements and the concrete stress ratios of the compressed flange surface under the ultimate limit stag were defined on the basis of FEM results. The reinforcement participation ratio (RPR) depicts the force proportions undertaken by tensile line elements on behave of steel wires and textile yarns including the webs and bottom plate at the same cross section. The concrete participation ratio (CPR) indicates the stress distribution on the top surface. The analyzed positions, A-B-C and D-E-F shadow areas for SCB, as shown in Figure 19, were selected in the serious crack regions at the web and bottom plate. The corresponding RPR and CPR results are shown in Figure 21. The participation ratios of tensile wires in SCB were apportioned by several wires near the webs, in which case the wire proportion contained in the webs was approximately $75 \%$. The textile yarns in the FCB had the same traits; however, the bearing proportions of the yarns near the webs were lower than in the case of SCB, slightly over $45 \%$, while the bearing proportions of those in the bottom plate were higher, which means the GFTG stress distribution between the longitudinal yarns is higher than the corresponding values for SWM. The surplus bearing capacity and excellent deformability of GFTG leads to the FCB failure modes, which makes the tension force redistribution likely. If summed along with the bottom plate width within the $80 \mathrm{~mm}$, this portion of RPR can be amount to $80 \%$. Similarly, the concrete web nodes on the top plate also withstand a higher compression stress ratio over 4 times as much as the mid compressed flange does. However, the CPR variation rate is considerably smaller than the RPR at the bottom, which indicates the comparatively good cooperation among the compressed concrete areas. Nonetheless, there exists no evident difference between SCB and FCB in terms of CPR. In other words, the area around the web bears the maximum load action, which provides an explanation for the sudden loss bearing capacity of SCB.

Thus, a simplified model for the ultimate limit stage can be defined by the analytic method in combination the test data and FEM results. The analytic method postulates 
that concrete crushing or bar yielding are the usual prerequisites, which does not represent the actual condition according to the abovementioned discussion. The crushing area in the top concrete plate flange within some width near the web is assumed, and the reinforcement-stress states in the webs and bottom plates are not calculated owing to the considerably lower than the tensile strength. Considering the actual crack extended into the compressed flange area, the limiting-flange height and web width can be respectively considered as the ultimate equivalent depth and width of the compressive zone during flexural analysis. Table 11 lists the ULs obtained from the tests, FEM and analytic method. As above, under flexural ultimate limit stage, the compression flange height can be assumed as the equivalent compression depth, that is, a flange width of 0.5-0.75 in the concrete compression area or GFTG tensile area can participate completely.

\section{Conclusion}

In this study, TRCCP experiments under axial and transverse loading were conducted, and the results were compared with those for SMRCCP. The test results were discussed and analyzed in terms of the ultimate load-bearing capacity, load-deflection profiles, load-strain relationships, and failure modes.

(1) TRCCP demonstrates similar comprehensive performances under axial and transverse loads, including the ultimate bearing capacity, failure modes and the wholeness of the panel in comparison with SMRCCP, although it exhibits slightly higher ultimate deformability. A type of pseudo-ductility in the case of TRCCP appears when GFTG is still in the elastic stage.

(2) The overlapping space GFTG grid possesses the same ability to restrain the concrete and ensure the cooperation of the panel; further, it and behaved in a manner similar to that of SWM to restrain the concrete efficiently, even if only simple overlapping can guarantee the textile-grid working anchorage. The pull-out failure mode did not occur.

(3) The typical analysis for TRCCP based on RC theory can be applied well if the hypothetical concretecrushing width or fiber yarn rapture width are determined appropriately.

In conclusion, TRCCP is a good fit with load-bearing members, such as wall panels, and light slab systems. Further studies such as those pertaining to the matching degree and optimization between concrete and GFTG should be performed to collect sufficient data, and the behaviors of large specimens subjected to complex loads should be researched.

Conflict of Interests: The authors declare that they have no known competing financial interests or personal relationships that could have appeared to influence the work reported in this paper.

Author Contributions: Junqing Hong and Hai Fang conceived of the presented idea. Shaofeng Zhang and Xunqian $\mathrm{Xu}$ carried out the experiment. Xunqian Xu and Honglei Xie wrote the manuscript. Honglei Xie and Yuntian Wang performed the analytic calculations and performed the numerical simulations.

Data availability: The raw/processed data required to reproduce these findings cannot be shared at this time as the data also forms part of an ongoing study.

Founding information: The research described here was supported by the National Natural Science Foundation of China (Grant No. 51778285), the Natural Science Foundation for Distinguished Young Scholars of Jiangsu Province (Grant No. BK20190034) and the Funds for Youth Creative Research Groups of Nanjing Tech University.

\section{References}

[1] Babaie, R., M. Abolfazli, and A. Fahimifar. Mechanical properties of steel and polymer fiber reinforced concrete. Journal of the Mechanical Behavior of Biomedical Materials, Vol. 28, No. 1, 2019, pp. 119-134.

[2] Peled, A., and A. Bentur. Effects of woven fabric geometry on the bonding performance of cement composites in mechanical performance. Advanced Cement Based Materials, Vol. 7, No. 1, 1998, pp. 20-27.

[3] He, K., Y. Chen, and W. Xie. Test on axial compression performance of nano-silica concrete-filled angle steel reinforced GFRP tubular column. Nanotechnology Reviews, Vol. 8, No. 1, 2019, pp. 523-538.

[4] Shakil, U. A., and S. B. A. Hassan. Behavior and properties of tin slag polyester polymer concrete confined with FRP composites under compression. Journal of the Mechanical Behavior of Materials, Vol. 29, No. 1, 2020, pp. 44-56.

[5] Kariou, F. A., S. P. Triantafyllou, D. A. Bournas, and L. N. Koutas. Out-of-plane response of masonry walls strengthened using textile-mortar system. Construction \& Building Materials, Vol. 165, 2018, pp. 769-781.

[6] Lee, S.-Y., and J.-G. Hwang. Finite element nonlinear transient modelling of carbon nanotubes reinforced fiber/polymer composite spherical shells with a cutout. Nanotechnology Reviews, Vol. 8, No. 1, 2019, pp. 444-451. 
[7] Hegger, J. and M. Horstmann. Light-weight TRC sandwich building envelopes. In: Mukesh, C. Limbachiya \& H. Y. Kew, Eds, Excellence in concrete construction through innovation: Proceedings of the International Conference on Concrete Construction, Kingston University, London, UK, 9-10 September 2008, Boca Raton: CRC Press, pp.187-194. DOI: https://doi.org/10.1201/ 9780203883440.ch27.

[8] De Sutter, S., O. Remy, T. Tysmans, and J. Wastiels. Development and experimental validation of a lightweight Stay-in-Place composite formwork for concrete beams. Construction \& Building Materials, Vol. 63, 2014, pp. 33-39.

[9] Huang, D., K. Wu, Y. Zhang, Z. Ni, X. Zhu, C. Zhu, et al. Recent Advances in Tissue plasminogen activator-based nanothrombolysis for ischemic stroke. Reviews on Advanced Materials Science, Vol. 58, No. 1, 2019, pp. 159-170.

[10] Djamai, Z. I., M. Bahrar, F. Salvatore, A. S. Larbi, and M. El Mankibi. Textile reinforced concrete multiscale mechanical modelling: Application to TRC sandwich panels. Finite Elements in Analysis and Design, Vol. 135, 2017, pp. 22-35.

[11] Bobylev, S. V., and A. G. Sheinerman. Effect of crack bridging on the toughening of ceramic/graphene composites. Reviews on Advanced Materials Science, Vol. 57, No. 1, 2019, pp. 54-62.

[12] Kerber, A., A. Gargano, K. Pingkarawat, and A. P. Mouritz. Explosive blast damage resistance of three-dimensional textile composites. Composites. Part A, Applied Science and Manufacturing, Vol. 100, 2017, pp. 170-182.

[13] Einea, A., D. C. Salmon, G. J. Fogarasi, T. D. Culp, and M. K. Tadros. State-of-the-art of precast concrete sandwich panels. PCI Journal, Vol. 36, No. 6, 1991, pp. 78-92.

[14] Zhang, H., L. Xiang, J. Zhu, J. Zhu, B. Chen, J. Yang, et al. Characterization of mechanical properties of epoxy/nanohybrid composites by nanoindentation. Nanotechnology Reviews, Vol. 9, No. 1, 2020, pp. 28-40.

[15] Colombo, I. G., M. Colombo, M. di Prisco, and F. Pouyaei. Analytical and numerical prediction of the bending behavior of textile reinforced concrete sandwich beams. Journal of Structural Engineering, Vol. 17, 2018, pp. 183-195.

[16] Babaie, R., M. Abolfazli, and A. Fahimifar. Mechanical properties of steel and polymer fiber reinforced concrete. Journal of the Mechanical Behavior of Biomedical Materials, Vol. 28, 2020, pp. 119-134.

[17] Portal, N. W., M. Flansbjer, K. Zandi, L. Wlasak, and K. Malag Bending behaviour of novel Textile Reinforced Concrete-foamed concrete (TRC-FC) sandwich elements. Composite Structures, Vol. 177, 2017, pp. 104-118.

[18] Tomlinson, D., and A. Fam. Analytical approach to flexural response of partially composite insulated concrete sandwich walls used for cladding. Engineering Structures, Vol. 122, 2016, pp. 251-266.

[19] Bai, F., and J. S. Davidson. Analysis of partially composite foam insulated concrete sandwich structures. Engineering Structures, Vol. 91, 2015, pp. 197-209.

[20] PCI Committee on Precast Concrete Sandwich Panels. State-ofthe-art of precast/prestressed sandwich wall panels. PCI Journal, Vol. 42, No. 2, 1997, pp. 1-61.

[21] Kang, W.-H., J.H. Kim, W. -H. Kang, and J. H. Kim. Reliability-based flexural design models for concrete sandwich wall panels with continuous GFRP shear connectors. Composites. Part B, Engineering, Vol. 89, 2016, pp. 340-351.
[22] Rizkalla, S. H., T. K. Hassan, and G. Lucier. FRP shear transfer mechanism for precast, prestressed concrete sandwich loadbearing panels. ACI Special Publications, Vol. 265, 2009, pp. 603-626.

[23] Pessiki, S., and A. Mlynarczyk. Experimental evaluation of the composite behavior of precast concrete sandwich wall panels. PCl Journal, Vol. 48, No. 2, 2003, pp. 54-71.

[24] Lee, B.-J., and S. Pessiki. Design and analysis of precast, prestressed concrete, three wythe sandwich wall panels. PCI Journal, Vol. 52, No. 4, 2007, pp. 70-83.

[25] Tomlinson, D., and A. Fam. Experimental investigation of precast concrete insulated sandwich panels with glass fiber-reinforced polymer shear connectors. ACI Structural Journal, Vol. 111, No. 3, 2014, pp. 595-606.

[26] Benayoune, A., A. A. A. Samad, D. N. Trikha, A. A. A. Ali, and A. A. Ashrabov. Structural behaviour of eccentrically loaded precast sandwich panels. Construction \& Building Materials, Vol. 20, No. 9, 2006, pp. 713-724.

[27] Benayoune, A., A. A. Samad, D. N. Trikha, A. A. Ali, and S. H. M. Ellinna. Flexural behaviour of pre-cast concrete sandwich composite panel experimental and theoretical investigations. Construction \& Building Materials, Vol. 22, No. 4, 2008, pp. 580592.

[28] Mohamad, N., A. I. Khalil, A. A. Abdul Samad, and W. I. Goh. Structural behavior of precast lightweight foam Concrete Sandwich panel with double shear truss connectors under flexural load. International Scholarly Research Notices, Vol. 2014, 2014, pp. 1-7.

[29] Frankl, B. A., G. W. Lucier, T. K. Hassan, and S. H. Rizkalla. Behavior of precast, prestressed concrete sandwich wall panels reinforced with CFRP shear grid. PCI Journal, Vol. 56, No. 2, 2011, pp. 42-54.

[30] Hassan, T. K., and S. H. Rizkalla. Analysis and design guidelines of precast prestressed concrete, composite load-bearing sandwich wall panels reinforced with CFRP grid. PCI Journal, Vol. 55, No. 2, 2010, pp. 147-162.

[31] Kim, J., and Y. -C. You. Composite behavior of a novel insulated concrete sandwich wall panel reinforced with GFRP shear grids: Effects of insulation types. Materials (Basel), Vol. 8, No. 3, 2015, pp. 899-913.

[32] Kang, W. -H., and J. Kim. Development of statistical design models for concrete sandwich panels with continuous glass-fiberreinforced polymer shear connectors. Advances in Structural Engineering, Vol. 19, No. 2, 2016, pp. 239-254.

[33] Naito, C., J. Hoemann, M. Beacraft, and B. Bewick. Performance and characterization of shear ties for use in insulated precast concrete sandwich wall panels. Journal of Structural Engineering, Vol. 138, No. 1, 2011, pp. 52-61.

[34] Cinar, K. Evaluation of sandwich panels with composite tubereinforced foam core under bending and flatwise compression. Journal of Sandwich Structures \& Materials, Vol. 22, No. 2, 2020, pp. 480-493.

[35] FZ/T01057.7. Test method for identification of textile fibers-Part 7: Density gradient column method.

[36] ASTM D4595-17. Standard Test Method for Tensile Properties of Geotextiles by the Wide-Width Strip Method, ASTM International.

[37] ASTM E8 / E8M-16a. Standard Test Methods for Tension Testing of Metallic Materials, ASTM International.

[38] ASTM C39 / C39M-18. Standard Test Method for Compressive Strength of Cylindrical Concrete Specimens. 